\title{
Pandemia de covid-19, ensino remoto e a potencialização das desigualdades educacionais*
}

\author{
Covid-19, distance education, and the \\ intensification of educational inequalities
}

\section{Rodrigo Cesar da Silva Magalhães ${ }^{i}$ \\ ' Professor de história, Colégio Pedro Il. Rio de Janeiro - RJ - Brasil \\ orcid.org/0000-0002-8142-9380 \\ rodrigocesa@hotmail.com}

Recebido em 11 ago. 2020.

Aprovado em 17 out. 2020.
MAGALHÃES, Rodrigo Cesar da Silva. Pandemia de covid-19, ensino remoto e a potencialização das desigualdades educacionais. História, Ciências, Saúde - Manguinhos, Rio de Janeiro, v.28, n.4, out.-dez. 2021, p.1263-1267.

\section{Resumo}

O presente artigo discute a adoção de modalidades de ensino remoto no contexto da pandemia de covid-19 e a potencialização das desigualdades educacionais no Brasil.

Palavras-chave: pandemia; covid-19; desigualdades educacionais; ensino remoto; educação a distância (EAD).

\section{Abstract}

This article discusses the adoption of distance education modalities within the context of the covid-19 pandemic and the intensification of educational inequalities in Brazil.

Keywords: pandemic; covid-19; educational inequalities; distance education. 
o dia 11 de março de 2020, a Organização Mundial da Saúde (OMS) classificou como
pandemia o surto de covid-19, doença causada pelo novo coronavírus (SARS-CoV-2), identificado pela primeira vez em seres humanos em dezembro de 2019, na cidade de Wuhan, na China. Aproximadamente um ano depois, os números eram assustadores: cerca de 110 milhões de casos confirmados e mais de dois milhões e meio de mortes no mundo (Folha..., s.d.). No Brasil já são mais de 250 mil mortos pela doença, na maior tragédia sanitária em um século (WHO..., s.d.).

A rápida propagação da covid-19 para todas as regiões do planeta e a inexistência inicial de uma vacina ou de qualquer medicamento antiviral específico e cientificamente comprovado capazes de, respectivamente, prevenir e tratar a doença levaram à implementação de quarentenas e lockdowns em vários países. Essas medidas extremas visavam garantir o distanciamento social e assim reduzir os níveis de contágio. A principal preocupação de governos do mundo inteiro era evitar o colapso dos sistemas de saúde de seus países, que poderia ocorrer se o número de doentes necessitando de internação fosse maior que o de leitos disponíveis nas unidades hospitalares.

Sistemas de educação ao redor do planeta também sentiram os efeitos da pandemia e enfrentaram um desafio sem precedentes. Relatório do Banco Mundial aponta que cerca de 1,4 bilhão de estudantes ficaram fora da escola em mais de 156 países (Políticas..., 2 abr. 2020). Na América Latina e no Caribe, mais de 154 milhões de crianças e adolescentes se encontravam na mesma situação, número que representa cerca de 95\% dos alunos matriculados na região, segundo estimativa do Fundo das Nações Unidas para a Infância (Covid-19..., 23 mar. 2020).

Nesse cenário, muitos foram os países que recorreram, com maior ou menor sucesso, à educação a distância (EAD) e variadas formas de ensino remoto para diminuir os impactos da pandemia sobre o cotidiano escolar. As alternativas iam desde aquelas que envolvem alta tecnologia, como a gravação de videoaulas em tempo real e sua disponibilização em plataformas online, até a produção de programas educativos para serem veiculados em emissoras de rádio e televisão. O Brasil também enveredou por esse caminho, o que tem revelado e, mais do que isso, acentuado uma desigualdade histórica e estrutural que marca a nossa sociedade: o acesso à educação, que a Constituição Federal (Brasil, 1988) considera um direito de todos (artigo 205, caput) e que tem como um de seus princípios "a igualdade de condições para o acesso e permanência na escola" (artigo 206, inciso I).

No dia 17 de março, já com as aulas suspensas no país, uma portaria do Ministério da Educação autorizou a substituição de aulas presenciais por aulas em meios digitais, pelo tempo que durar a pandemia de covid-19, em toda a rede federal de ensino, que engloba as universidades e institutos federais, bem como as universidades e faculdades privadas (Brasil, 18 mar. 2020; MEC autoriza..., 18 mar. 2020). A portaria do governo federal abriu caminho para que as redes estaduais e municipais de ensino do país também adotassem medidas visando à implementação do ensino remoto, modalidade já utilizada em muitas escolas particulares. Essa solução desconsiderou, por exemplo, as especificidades da educação infantil, na qual as crianças aprendem de forma lúdica, com brincadeiras e por meio do acolhimento e da interação, uma realidade que o ensino a distância mediado por tecnologias digitais é incapaz de reproduzir, independentemente da classe social e do nível 
de formação dos membros da família dessas crianças. Além de inadequada, a utilização de EAD ou quaisquer outras atividades escolares remotas na educação infantil é também ilegal, pois não está prevista na Lei de Diretrizes e Bases da Educação Nacional (Brasil, 23 dez. 1996), nem mesmo em situações emergenciais, como acontece com o ensino fundamental (Educação..., s.d.).

Fato é que a EAD e outras formas de ensino remoto mediadas por plataformas tecnológicas, aplicativos de celulares, rádio e televisão vêm sendo incentivadas pelas três esferas de governo, muitas vezes à revelia da legislação educacional vigente no país, e adotadas em larga escala, principalmente na rede privada de ensino. Esse processo, desencadeado em meio a uma pandemia, além de maximizar a exploração dos professores e jogar sobre eles grande parte do ônus causado pelo fechamento das escolas, também tem contribuído para descortinar as diferentes realidades em que vivem os estudantes brasileiros e de que modo elas afetam seu direito constitucional à educação.

De acordo com o Instituto Trata Brasil, que se baseia em dados do Sistema Nacional de Informações sobre Saneamento, 35 milhões de brasileiros não têm acesso à água tratada (Água, s.d.) e outros 100 milhões vivem em locais sem coleta e tratamento de esgoto (Esgoto, s.d.). No que concerne ao uso de diferentes tecnologias nos domicílios brasileiros, a pesquisa TIC Domicílios 2018 apontou que 30\% das residências do país não têm acesso à internet, porcentagem que sobe para $50 \%$ se considerarmos as áreas rurais. O estudo mostrou também que entre as classes D e E, 85\% se conectam à internet exclusivamente pelo celular, $2 \%$ apenas pelo computador e 13\% por ambos os dispositivos (Pesquisa..., 2019). Os números não deixam dúvidas sobre quais parcelas da sociedade brasileira têm condições de acompanhar as atividades pedagógicas digitais, caso políticas públicas que tenham como objetivo a universalização do acesso à internet não sejam colocadas em prática. Isso é o que prevê, aliás, o Marco Civil da Internet, lei sancionada em abril de 2014, ao estabelecer o acesso à rede mundial de computadores como um serviço essencial, que, portanto, deve ser garantido a todos (Brasil, 23 abr. 2014).

Além dos dados apresentados, qualquer medida que vise estimular a EAD ou formas de ensino remoto no país deve considerar também a realidade daqueles estudantes que têm alguma responsabilidade doméstica, aqueles que precisam trabalhar em idade escolar e os que, embora tenham celular, não podem pagar por um pacote de dados suficiente para acessar plataformas e aplicativos educacionais. Cabe destacar também que muitos estudantes brasileiros tiveram, infelizmente, familiares doentes, que perderam o emprego ou que faleceram em virtude da pandemia de covid-19, e que um número considerável está enfrentando problemas graves de alimentação, pois, para muitos, a merenda escolar é a única refeição diária. O problema para essas crianças e adolescentes vai muito além das dificuldades de acesso às mais modernas tecnologias. Elas não têm garantidas as condições mínimas de segurança alimentar e de saúde física e mental, sem as quais viver se torna uma tarefa extremamente difícil, e estudar, praticamente impossível.

Desse modo, como se o enfrentamento de uma crise sanitária de grande magnitude não fosse, por si só, uma tarefa árdua, para a qual o governo federal tem contribuído muito pouco, chegando até mesmo a prejudicar parte dos esforços, essa luta ainda vem acompanhada de outros obstáculos para grandes contingentes da população brasileira, tais 
como a falta de saneamento básico, de alimentação adequada, de moradia, dificuldades de acesso ao sistema de saúde, sucateamento do Sistema Único de Saúde e ataques aos direitos trabalhistas, para citar apenas alguns.

Nessa triste realidade, aceita com normalidade por uma parcela da sociedade, é difícil imaginar que esse número gigantesco de cidadãos brasileiros desassistidos pelo Estado em seus direitos básicos, que não têm água tratada para lavar as mãos e realizar sua higiene pessoal, tenha condições de estudar a distância por meio de tecnologias digitais. É o que argumenta o Sindicato Nacional dos Docentes das Instituições de Ensino Superior, que, em reunião extraordinária de seu conselho, realizada em setembro, se posicionou de forma contrária ao ensino remoto emergencial (Andes-SN, 1 out. 2020). Entendimento semelhante tem a Federação de Sindicatos de Trabalhadores Técnico-Administrativos em Instituições de Ensino Superior Públicas do Brasil (Modelo..., 23 jun. 2020), bem como o Sindicato Nacional dos Servidores Federais da Educação Básica, Profissional e Tecnológica ao argumentar que a elaboração das propostas de ensino remoto emergencial seja precedida de um amplo levantamento junto à comunidade acadêmica sobre as condições de trabalho, ensino e aprendizagem (Ensino..., 10 ago. 2020). Essa, no entanto, não parece ser a preocupação de gestores educacionais das três esferas de governo e de organizações privadas como Itaú Social, Fundação Lemann, Google e Laureate, entre outras, que, apesar das críticas de sindicatos e movimentos sociais ligados à educação, professores e intelectuais, têm feito grandes investimentos em tecnologias para o ensino remoto.

A situação de excepcionalidade na qual nos encontramos não dá ao governo federal o direito de criar barreiras no acesso à educação, sobretudo para crianças e adolescentes que já se encontram em situação de vulnerabilidade. Antes de pensar em EAD e em outras modalidades de ensino remoto, é necessário massificar os investimentos em educação e desenvolver políticas públicas nesse campo que levem em consideração as condições sociais e econômicas em que vive a maior parte dos estudantes brasileiros, principalmente os mais pobres e vulneráveis, sobre os quais as consequências da pandemia de covid-19 têm se abatido com mais gravidade. Na atual realidade brasileira, a EAD ou qualquer outra forma de ensino remoto mediado por tecnologias digitais só faz sentido para aqueles que enxergam a educação como uma atividade excludente que, em vez de atenuar, potencializa as desigualdades sociais e econômicas do país.

\section{NOTA}

${ }^{1} \mathrm{O}$ presente texto é uma versão mais completa, atualizada e submetida a revisão por pares de uma postagem veiculada no blog de História, Ciências, Saúde - Manguinhos.

\section{REFERÊNCIAS}

ÁGUA. Trata Brasil: Saneamento é saúde, s.d. Disponível em: http://www.tratabrasil.org.br/ saneamento/principais-estatisticas/no-brasil/ agua. Acesso em: 7 ago. 2020.

ANDES-SN, Sindicato Nacional dos Docentes das Instituições de Ensino Superior. Circular n.333/20,
1 out. 2020. Disponível em: https://adufs.org.br/ manager/resources/uploads/arquivos/Circ33320(1).pdf. Acesso em: 9 out. 2020.

BRASIL. Ministério da Educação. Gabinete do Ministro. Portaria n.343, de 17 de março de 2020. Dispõe sobre a substituição das 
aulas presenciais por aulas em meios digitais enquanto durar a situação de pandemia do Novo Coronavírus - COVID-19. Diário Oficial da União, edição 53, seção 1, p.39, 18 mar. 2020. Disponível em: http://www.in.gov.br/ en/web/dou/-/portaria-n-343-de-17-de-marcode-2020-248564376. Acesso em: 7 ago. 2020.

BRASIL. Lei n.12.965, de 23 de abril de 2014. Estabelece princípios, garantias, direitos e deveres para o uso da internet no Brasil. Brasília, DF: Presidência da República, 23 abr. 2014. Disponível em: http://www.planalto.gov.br/ ccivil_03/_ato2011-2014/2014/lei/112965.htm. Acesso em: 7 ago. 2020.

BRASIL. Lei n.9.394, de 20 de dezembro de 1996. Estabelece as Diretrizes e Bases da Educação Nacional. Diário Oficial da União, seção 1, ano 134, n.248, p.27839, 23 dez. 1996. Disponível em: http://www.planalto.gov.br/ccivil_03/leis/ 19394.htm. Acesso em: 5 abr. 2021.

BRASIL. Constituição da República Federativa do Brasil. Brasília, DF: Senado Federal/Centro Gráfico, 1988.

COVID-19: mais de 95\% das crianças estão fora da escola na América Latina e no Caribe, estima o Unicef, 23 mar. 2020. Disponível em: https://www.unicef.org/brazil/comunicadosde-imprensa/covid-19-mais-de-95-por-centodas-criancas-fora-da-escola-na-america-latina-ecaribe. Acesso em: 7 ago. 2020.

EDUCAÇÃO a distância na educação infantil, não!, s.d. Disponível em: http://www.anped.org. br/sites/default/files/images/manifesto_anped_ ead_educacao_infantil_abril_2020.pdf. Acesso em: 7 ago. 2020.

ENSINO remoto sem levantamento abrangente sobre as condições de estudantes, docentes e técnicos? Tô fora!, 10 ago. 2020. Disponível em: https://sinasefe.org.br/site/ensino-remoto-sem- levantamento-abrangente-sobre-as-condicoesde-estudantes-docentes-e-tecnicos-to-fora. Acesso em: 9 out. 2020.

ESGOTO. Trata Brasil: Saneamento é saúde, s.d. Disponível em: http://www.tratabrasil.org.br/ saneamento/principais-estatisticas/no-brasil/ esgoto. Acesso em: 7 ago. 2020.

FOLHA informativa sobre ccovid-19, s.d. Disponível em: https://www.paho.org/pt/ covid19. Acesso em: 24 fev. 2021.

MEC AUTORIZA ensino a distância em cursos presenciais, 18 mar. 2020. Disponível em: http://portal.mec.gov.br/component/content/ article?id=86441. Acesso em: 7 ago. 2020 .

MODELO de ensino remoto é inacessível a maior parte dos estudantes, s.d. Disponível em: https://fasubra.org.br/noticias/modelo-deensino-remoto-e-inacessivel-a-maior-parte-dosestudantes. Acesso em: 9 out. 2020.

PESQUISA sobre o uso das tecnologias de informação e comunicação nos domicílios brasileiros: TIC domicílios 2018. São Paulo: Comitê Gestor da Internet no Brasil, 2019. Disponível em: https://www.cetic.br/media/docs/ publicacoes/2/12225320191028-tic_dom_2018_ livro_eletronico.pdf. Acesso em: 7 ago. 2020.

POLÍTICAS educacionais na pandemia da covid-19: o que o Brasil pode aprender com o resto do mundo?, 2 abr. 2020. Disponível em: http://pubdocs.worldbank.org/ en/413781585870205922/pdf/POLITICASEDUCACIONAIS-NA-PANDEMIA-DA-COVID19-O-QUE-O-BRASIL-PODE-APRENDER-COMO-RESTO-DO-MUNDO.pdf. Acesso em: 7 ago. 2020.

WHO Coronavirus Disease (covid-19) Dashboard, s.d. Disponível em: https://covid19. who.int. Acesso em: 24 fev. 2021.

\section{$\rightarrow \rightarrow \rightarrow<<$}

